\title{
RELACIONES ENTRE AFRICANOS E INDÍGENAS EN CHIAPAS Y GUATEMALA
}

\author{
Juan Pablo Peña Vicenteño
}

Resumen: La presencia africana en la Audiencia de Guatemala en los siglos xVI y xVII ha sido poco estudiada. Por lo tanto, en este trabajo se analizarán los diferentes mecanismos que utilizó la corona española para el traslado de esclavos, como las licencias y el sistema de asientos. Asimismo, se estudiará la inserción de los africanos en la sociedad colonial y principalmente su interrelación con la población indígena nativa de la región.

En los documentos coloniales referentes a matrimonios, podemos observar los procesos de "interculturalidad" en los cuales el esclavo africano intercambió elementos culturales que influyeron en la música. Tal fue el caso de la marimba, instrumento que dio identidad a la región de estudio. Por último, se pretende observar, a través del análisis de las narrativas indígenas originadas en la década de los 90' del siglo xx, cómo en la cosmovisión indígena aún continúa la presencia de los "negros".

Palabras clave: esclavos africanos, relaciones interculturales, comercio de esclavos en el Océano Atlántico, Audiencia de Guatemala, marimba.

Abstract: The presence of African population at the "Audiencia" of Guatemala between $16^{\text {th }}$ and $17^{\text {th }}$ centuries has been vaguely studied by historians and other social scientists. This paper emphasizes on several ways - as slave trade licenses and 'asientos' - that were used by the Spanish Crown for slave trade and transportation.

In addition, this article analyses the integration of African slaves and their descendents in Colonial Mexican society, especially their mixture with indigenous population.

In Colonial records, as marriages and baptisms files, it is possibly to regard a profound influence on inter-cultural processes between African people and the rest of the Colonial casts. As an example, the musical instrument 'marimba' that brought cultural identity to Guatemala 'Audiencia'. Finally, in this article we will analyze the indigenous literature of the last decade of the $20^{\text {th }}$ century, in which is clear the evidence of "negro" agents in indigenous cosmology.

Keywords: African slaves, Inter-cultural relations, Atlantic slave trade, "Audiencia" of Guatemala, 'marimba'.

Recepción: 9 de noviembre de 2007.

Aceptación: 7 de octubre de 2008. 



\title{
RELACIONES ENTRE AFRICANOS E INDÍGENAS EN CHIAPAS Y GUATEMALA
}

\author{
Juan Pablo Peña Vicenteño \\ Proyecto Afroamérica. La Tercera Raíz. \\ Programa Universitario México Nación Multicultural, unam
}

Las investigaciones sobre la presencia africana en Chiapas y Guatemala han sido estudiadas desde dos diferentes ópticas: la antropología y la historia. Esta investigación la inicié a partir de la lectura de dos artículos sobre antropología física en el libro Los legítimos hombres. Aproximaciones antropológicas al grupo tojolabal, editado por Mario Humberto Ruz. En él se encuentran dos artículos, el primero de Carlos Serrano "Los grupos sanguíneos (sistema ABO) y el mestizaje en los tojolabales de Chiapas", ${ }^{1}$ se menciona que el tipo de sangre de los tojolabales tiene el tipo B, muy común en los africanos. Aunque el investigador sólo cita un documento de 1807 , comenta que es muy probable que esta influencia se halla generado por el mestizaje entre los tojolabales.

Por su parte, Julieta Aréchiga en su artículo, "Dermatoglifos dígito-palmares en un grupo maya tojolabal" 2 explica que en los dermatoglifos de las palmas es donde se presentan mayores divergencias entre los distintos grupos raciales, y que la evaluación de una posible mezcla de los tojolabales con grupos blancos y negros se debe a que éstos estuvieron en constante contacto.

A partir de éstos inicié la búsqueda en los diferentes archivos históricos, como el Archivo Histórico Diocesano en San Cristóbal de las Casas, Chiapas, y el Archivo General de Centroamérica, ubicado en la ciudad de Guatemala; en ambos, los documentos reflejan la presencia de africanos y afrodescendientes.

Por otro lado, Luz María Martínez Montiel, en su libro Afroamérica. I. La Ruta del esclavo. ${ }^{3}$ Se dedica al estudio del comercio triangular y la trata trasatlántica, hace énfasis en el proceso de traslado de la población africana al Nuevo Mundo. Además, realiza una sistematización de la trata de esclavos, desde su desplazamiento del interior de África hasta su integración en el sistema económico de América; así explica las repercusiones que hubo en los dos continentes involucrados en el comercio negrero.

Finalmente, el libro de Juan González Esponda, Negros, pardos y mulatos. Otra historia que contar, ${ }^{4}$ es un estudio general sobre la población africana y sus des-

1 Mario Humberto Ruz, Los legítimos hombres, Aproximaciones antropológicas al grupo tojolabal, 1982.

2 Ibidem.

${ }^{3}$ Idem. Afroamérica I. La ruta del esclavo. 2006.

${ }^{4}$ Juan González Esponda. Negro, Pardos y Mulatos: Otra historia que contar. 2002. 
cendientes en el estado de Chiapas. Su principal fuente documental es el Archivo Histórico Diocesano, el cual carece de manuscritos referentes al siglo xvi y la primera mitad del siglo xvII, en lo que a la población africana se refiere. La principal preocupación de Esponda es dar a conocer la existencia de la esclavitud africana y el mestizaje en Chiapas.

Como sabemos, la provincia de Chiapa perteneció a la gobernación de Pedro de Alvarado, quien solicitó al Rey que le otorgara dicho territorio para poblarlo y evangelizar a la población en ella residente. A la muerte de Alvarado se organizó la llamada Audiencia de los Confines, la cual se instaló en un primer momento en Gracias a Dios, y posteriormente se trasladó a la ciudad de Santiago de los Caballeros, en Guatemala, donde iniciaron los procesos de colonización y evangelización de las diferentes provincias que componían la Audiencia de Guatemala. Es decir, El Salvador, Honduras, Nicaragua, Costa Rica y la provincia de Chiapa.

A partir de esta nueva organización gubernamental que emprendió la Corona española y a partir de la emisión de las Leyes Nuevas en 1542, donde se abolía la esclavitud de la población indígena, se iniciaron las entradas de africanos a la región centroamericana. El proceso de introducción de africanos se dio en varias etapas; la primera fue la de las licencias, las cuales eran otorgadas a los funcionarios reales y a los obispos principalmente, y éstas consistían en otorgar de tres a cinco esclavos africanos para su servicio en tierras americanas.

En el caso del territorio centroamericano, las licencias tuvieron que ver con varios comerciantes de la región. Autores como Juan González Esponda y Silvia Soriano, ${ }^{6}$ mencionan que uno de los principales introductores de esclavos africanos mediante el comercio negrero fue Pedro de Alvarado, pues apuntan que en sus tropas de conquista llevaba algunos negros esclavos para su servicio, y que posteriormente introdujo 200 esclavos africanos para utilizarlos como mano de obra.

Sin embargo, Gudrun Lenkersdorf, en su libro Génesis histórica de Chiapa, 15221532, señala que Alvarado efectivamente tenía todo el interés por emprender el comercio de esclavos negros. ${ }^{7}$ Para ello comenzó tratos con Francisco de Cobos, secretario del rey, y don Diego Beltrán, miembro del Concejo de Indias. Las licencias para traficar esclavos ya estaban aprobadas, pero el proyecto nunca prosperó debido a cuestiones políticas y familiares, de modo que Alvarado no pudo comenzar con dicho negocio.

Cabe señalar que este personaje era ya experto en el negocio de tráfico de humanos, pues Murdo Macleod comenta que después de la conquista en la región de Centroamérica, Alvarado comenzó a comerciar con esclavos indígenas a regiones como el Caribe, Panamá y Perú. ${ }^{8}$

${ }^{5}$ Idem.

6 "Aportes sobre mestizaje de esclavos africanos en Chiapas colonial", 1994.

${ }^{7}$ Gudrun Lenkersdorf. Génesis histórica de Chiapa, 1522-1532, p. 243.

${ }^{8}$ Murdo Macleod. Historia socio-económica de la América Central española. 1520-1720, p. 49. 
Además, las licencias no sólo fueron concedidas a los colonos y conquistadores, sino también a los eclesiásticos. En su caso, el trabajo de esclavos africanos fue implementado en las haciendas, pero el clero, sobre todo la orden dominica, impulsaba las Leyes Nuevas. Para contextualizar cabe decir que durante los años cuarenta del siglo xvı, tras la llegada de los obispos Valdivieso y Pedraza, se reforzaron las ideas liberadoras de indios del fraile Bartolomé de las Casas, pues ellos comenzaron a difundir las ideas de la abolición de la esclavitud india. Los encomenderos no estuvieron de acuerdo con estas ideas, al grado que fue asesinado el obispo Valdivieso en Nicaragua por los hijos del gobernante Contreras. ${ }^{9}$

En este contexto, se nombró como obispo de Chiapa al fraile Juan Ortega, a quien le otorgaron una licencia para pasar tres esclavos negros, libres de derechos por Cédula Real del 23 de agosto de 1598. Esto quiere decir libre de impuestos, sin embargo, el obispo nunca llegó al obispado; el obispo Andrés de Urbina posteriormente introdujo también tres esclavos. ${ }^{10}$

Entre las licencias otorgadas a eclesiásticos se hallan las concedidas a fray Bartolomé de las Casas. Le otorgaron cuatro esclavos africanos autorizados por el Rey en Cédula del 13 de febrero de $1544 .{ }^{11}$ Asimismo, al obispo de 1568, fray Tomás de Castilla, se le otorgaron licencias para tener esclavos a su servicio.

Es evidente que las coyunturas políticas y económicas que España vivía en 1555; es decir, al retiro de Carlos I y la subida al trono de Felipe II, tuvieron que ver con los cambios estructurales del comercio mercantil que este reino ya había comenzado desde el descubrimiento de América. La unión de la corona lusitana y la española en 1580 reforzó y amplió de manera general el comercio mercantil y en el caso particular que nos compete, la trata trasatlántica, implementándose así los asientos.

Tras los cambios políticos en la Península Ibérica, se tuvieron que crear nuevos causes en el comercio de esclavos. Debido a la coyuntura política, el comercio de africanos seguía en su mayoría en manos de los portugueses, pues era evidente su amplia experiencia histórica en la trata, lo cual culminó en la implantación de los asientos.

Asiento se le llamó al sistema mercantilista que pretendía una mejor distribución de esclavos en la América española. Se buscaba que este sistema lograra obtener mayores ganancias y tener una mayor administración en cuanto a la trata de esclavos. Felipe II confió a los portugueses este reparto y comercialización, y en 1580 se firmaron tratos con los rendeiros o contratistas de Portugal, quines tenían en su poder el marcado africano. Los tres puntos principales donde se concentraban los esclavos en las factorías eran: Cabo Verde, la isla de Santo Tomé y Angola, en cuya capital — San Pablo Loanda- hubo un incremento económico. ${ }^{12}$

\footnotetext{
${ }^{9}$ Ibidem, p. 92.

${ }^{10}$ Juan González Esponda, op. cit., p. 39.

11 Ibidem, p. 38.

12 Enriqueta Vila Vilar. Hispanoamérica y El comercio de esclavos. 1997, p. 23.
} 
Al puerto de Sevilla arribaron comerciantes y traficantes de esclavos portugueses para tramitar los diferentes permisos, con la finalidad de obtener la autorización del traslado de africanos. El rey estaba comprometido con los portugueses a otorgarles más licencias y permisos, lo que originó que se generara un descontento entre los comerciantes españoles; sin embargo, la Corona tuvo que implementar una serie de medidas de control para poder dar mayor apertura e igualdad de oportunidades a los españoles tratantes, otorgándoles licencias. Es importante mencionar que éstas siguieron en uso, pero sólo las encontramos en dos aspectos: 1) en cada asiento, el rey tenía un número determinado de licencias y él las otorgaba a los oficiales reales de la Casa de Contratación, a quienes les encargaba vigilar los fraudes cometidos por los asentistas; 2) concesiones especiales, ya sea a órdenes religiosas, rendeiros o bien a algún funcionario español o lusitano. ${ }^{13}$

El objetivo fundamental de los asientos era conseguir mayores ganancias para la Corona, y para ello se elevaron las rentas lo más alto posible y se estableció un control más riguroso sobre la cantidad de esclavos que se transportaban a América, pues siempre había la posibilidad de que los asentistas disfrazaran las cifras y ellos mismos vendieran a los negros obteniendo mayores beneficios.

La consolidación del sistema de asientos se produjo en 1594, después de la firma de contratos entre Felipe II y los comerciantes portugueses; éstos comenzaron a llevar a los esclavos a los diferentes puertos que demandaban la mercancía y que la Casa de Contratación designaba previamente. ${ }^{14}$ Pero, a su llegada a América, los asentistas tenían prohibido llevar a los esclavos tierra adentro y comercializarlos. Su obligación era sólo desembarcarlos y ahí los funcionarios de la Corona se encargaban de la venta y distribución.

Otro sistema de introducción de esclavos a la región de Centroamérica fue el contrabando. Se generó desde el inicio del comercio entre Europa, África y América, siendo un mecanismo implementado por los súbditos de las coronas europeas que tenían interés en el comercio trasatlántico, pues ya se había demostrado que dicho negocio dejaba buenos dividendos. Las potencias europeas como Holanda, Inglaterra, Francia y Dinamarca, entre otros reinos, empezaron a combatir los monopolios que Portugal y España tenían, optando por el comercio ilegal de mercancías, ya que este método reducía notablemente los costos.

De 1640 a 1692 el contrabando tuvo uno de sus momentos culminantes, ya que la dirección española de la trata negrera estaba inmersa en conflictos internos; además, las luchas de poder entre el Consejo de Indias y la Casa de Contratación, entre otros factores, contribuyeron a este auge. El comercio con América y la administración española estaba sumido en una serie de normatividades que provocaron alzas de precios, poca afluencia de barcos negreros y, por supuesto,

13 Ibídem, p. 54.

${ }^{14}$ Ibídem, p. 33.

${ }^{15}$ Presidente de la Audiencia de Guatemala de1626 a 1633. Murdo Macleod, op. cit., p. 329. 
pocas ventas legales de esclavos. Por lo tanto, los comerciantes americanos accedieron a las ofertas que los contrabandistas les ofrecían.

Casi todas las potencias antes mencionadas tenían posesiones estratégicas tanto en África como en América. Holanda, por ejemplo, se apoderó de Santo Tomé en 1599; Inglaterra, a su vez, se apropió de Jamaica y así comenzó su fortalecimiento en el comercio de esclavos, desplazando a Portugal. España, luego de su separación con Portugal en 1640, perdió todo control de África, aunque en 1647 los portugueses les permitían la compra de esclavos en Guinea a los traficantes españoles.

Las medidas de control fueron una de las estrategias de la Corona española para evitar pérdidas comerciales, aunque no tuvieron mucho éxito, pues era evidente que a los habitantes europeos en América les era más fácil, cómodo y rápido, obtener mercancías de manera ilegal.

La Audiencia de Guatemala no fue excepción, también se vio inmersa en el contrabando; sin embargo, no contamos con información acerca de la compraventa de esclavos a través de este sistema, tampoco contamos con fuentes que nos ayuden a saber más acerca del movimiento comercial de las mercancías, ni mucho menos la oferta y la demanda.

Sabemos que la región de lo que actualmente es Belize fue un puesto importante para los piratas ingleses; quienes se asentaron en sus costas en el año de 1638, así como del territorio de Campeche, en específico de la Laguna de Términos. Esta última región fue constantemente peleada por la Corona Española y los piratas, finalmente la ganó España.

Los puertos más importantes de la Audiencia de Guatemala fueron Puerto Caballos, Trujillo y Santo Tomás de Castilla, y debido a su cercanía con la costa beliceña y la de Jamaica fueron puertos que tuvieron constantes ataques piratas. Existe un manuscrito clave para confirmar que sí existieron arribos de piratas:

Don Diego de Acuña, ${ }^{15}$ mi gobernador y Capitán General de la provincia de Guatemala y presidente de mi Audiencia Real que en ella reside, vuestra carta de catorce de enero de este año se ha visto en mi Junta de Guerra de las Indias.

Decís que los puertos de esa provincia están prevenidos lo mejor que se ha podido y ha dado lugar la cortedad de esa tierra y el poco dinero que hay en ella, y por que los puertos de Santo Thomas de Castilla y de Truxillo que son de más importancia y riesgo conviene fortificarlos, y pedir que se os de, pues en cédula para que podáis gastar de mi Real hacienda lo que fuese necesario en su fortificación, avisarme heiss por menos en la forma que se podrá haga lo que pedís. ${ }^{16}$

En la región de Chiapas el contrabando estuvo presente sobre todo en los caminos o rutas comerciales, es decir, los contrabandistas llegaban a los principales puertos de entrada y de ahí distribuían la mercancía, muchos esclavos

${ }^{16}$ AGCA. A1.23 Leg. 1516 Fol. 57. Año 1632. 
que estuvieron en las empresas coloniales fueron introducidos por esta vía. Sin embargo, no tenemos los suficientes documentos que especifiquen la compra de esclavos de esta forma.

La interculturalidad ${ }^{17}$ en la Audiencia de Guatemala no ha sido estudiada del todo. Christopher Lutz analiza el mestizaje, el matrimonio y las relaciones amoesclavo en Santiago de Guatemala; además, el autor estudia el fuerte mestizaje en la colonia centroamericana. No obstante, habría que enfatizar el estudio de las relaciones entre los esclavos africanos, los afrodescendientes y los indígenas.

Es importante señalar que las ordenanzas de la Corona prohibían que los esclavos africanos residieran en las Repúblicas de Indias. Tal es el caso de la emitida el 2 de mayo de 1563 por Felipe II, quien dictaba que en los pueblos de indios no podían vivir ni españoles ni negros ni mestizos ni mulatos, aunque no fue del todo posible separar al indígena del africano.

En la región centroamericana no fue factible que el esclavo africano estuviera desligado de las comunidades indígenas, pues existen numerosos documentos en los que se refleja el mestizaje y las relaciones entre los dos grupos sociales más numerosos, el indígena y el africano.

González Esponda (2002) enumera -en su apéndice 1- las diversas defunciones de 1650 a 1660 de esclavos y mulatos, lo cual nos da un referente de las relaciones interétnicas, pues en dicha relación se mencionan los matrimonios de los negros y mulatos sobre todo con indígenas.

Las empresas que la Corona instauró en la Audiencia de Guatemala, entre éstas la minería, en la provincia de Honduras y Nicaragua; las plantaciones e ingenios de azúcar; el cacao en la región del Soconusco y el Salvador, y los obrajes de añil; fueron centros donde el esclavo africano muchas veces convivió con los indígenas.

Las relaciones entre africanos e indígenas fueron muy frecuentes en la provincia de Chiapa. Silvia Soriano ${ }^{18}$ nos relata el proceso seguido contra Nicolás de Santiago, quien era un zambo libre. Trabajaba en la finca cacaotera de Ixtacomitán, llamada Nuestra Señora del Rosario y estaba acusado de hechicería y superstición. Los padres de este mulato fueron una india del pueblo zoque llamado Nicapa y un mulato libre. Además, Nicolás había trabajado en las haciendas ganaderas de Chiapa de los indios, ahí se casó con una indígena y tuvo tres hijos. Enviudó y se trasladó a Jiquipilas donde trabajó como caporal de una estancia de ganado llamada Macuilapa. Se volvió a casar con una mulata libre y tuvieron seis hijos.

Este caso refleja que la comunicación, a partir del trabajo del afrodescendiente y el indígena, tuvo repercusiones en el fuerte mestizaje que se generó en la

\footnotetext{
${ }^{17}$ Se entiende por interculturalidad al concepto que "hace hincapié en la importancia de las relaciones horizontales y sin pretensiones de dominación ni ejercicios de poder entre los pueblos". Véase Olivé León, Interculturalismo y justicia social. 2004, p. 24.

${ }^{18}$ Silvia Soriano, "Aportes sobre el mestizaje de esclavos africanos en Chiapas Colonial", 1994.
} 
provincia de Chiapa. Estas relaciones interculturales se verán reflejadas a lo largo de la época colonial centroamericana; sobre todo porque siendo una región en su mayoría indígena, las relaciones interpersonales se buscaban con personas de la misma clase social. No obstante, no siempre fue así.

Es muy probable que existieran relaciones de europeos y criollos con personas de origen africano; como lo refleja un documento de 1591. En él, Hernando Díaz, un mulato, es protegido por su ama Andonza, quien se dedica a apoyarlo para que le sea reconocida su libertad. Aunque, se debe aclarar que no se encontró ningún documento - no por ello debe entenderse que no existe- en el que se refleje la unión marital entre europeas y africanos de manera legal; pues, las esclavas que desempeñaban labores domésticas seguramente estuvieron más involucradas con europeos que con los indígenas. El caso de Hernando Díaz es muy peculiar, la relación que tenía con sus amos era de manera efímera; él era hijo de uno de los encomenderos más fuertes de San Salvador, Diego Díaz de la Reguera.

El mulato nunca perdió su condición de esclavo a pesar de que era hijo de este encomendero, no obstante, su condición de mulato le permitió tener mayores atributos. El caso jurídico es muy impresionante: Diego Ordóñez de Villaquirán, vecino de Ciudad Real, se casa con la ama Aldonza, y como parte de la dote se le otorgan tres esclavos: Hernando Díaz, su madre y su hermana. Al solicitar los bienes de su esposa, Ordóñez solicita que se le envíen sus esclavos a la encomienda que tiene en Ciudad Real, pero su esposa Aldonza, defiende a Hernando Díaz, su primo, para que pueda obtener la libertad. Por ello este caso es tan singular, pues refleja las relaciones tan estrechas entre españoles y africanos.

Otro caso interesante es el del negro Manuel, quien es libre. El manuscrito es un inventario de los bienes del negro, elaborado por los alcaldes de la localidad en $1611 .{ }^{19}$ Las propiedades de Manuel se subastaron y lo recaudado pasa a manos de las autoridades de Ciudad Real. No obstante, conforme se va exponiendo el proceso, aparece una contrademanda de una indígena llamada María quien afirma ser la esposa de Manuel. El proceso se extiende a lo largo de unas 27 fojas, donde se pelean los bienes del negro. Nuevamente, la mujer del negro solicita los bienes, hasta que al fin le son entregados.

El documento comprueba cómo los libertos podían tener acceso a bienes: se hizo un inventario debido a que las autoridades creyeron que el difunto no tenía herederos, se adjudicaron los bienes para ofrecerlos en almoneda:

Inventario. Principalmente se inventarió cuatro mullas de carga.

Y también tres machos de Asia

Y también cinco, al parecer viejos,

Y también dos lechones

Y también otros tres lechoncillos por capar,

${ }^{19}$ AGCA.A (1) Leg. 235, Exp. 1705 Año 1611. 
Y también una casa de pichones y paja

Y también tres sillas de asentar de madera,

Y un capote viejo de paño burdo.

Y también una silla vieja jineta con sus estribos de fierro

Y también un freno de mula,

Y también pareció una caja cerrada en el que se hallo lo siguiente:

Y se desarrajó por no haber hallado pa...,

Y se halló en ella un testimonio de cómo el dicho Juan era libre conforme a la clausula del testamento de dicho Mario Juan, difunto, y tambien una bulas.

Y tambien unas cartas de pago sin otro. ${ }^{20}$

La viuda reclama las propiedades de su esposo alegando que está casada por la Iglesia y que por ley le corresponden los bienes; pero los bienes se rematan en venta pública, y sólo se le da a la esposa una remuneración de ellos. Las autoridades alegan que los bienes ya eran propiedad de Manuel antes de su matrimonio, y que, por lo tanto, no tiene efecto la apelación de la viuda.

Manuel tuvo la oportunidad de adquirir los bienes después de que se casó con María Vázquez, una indígena del mismo pueblo de Chenalhó. Las autoridades de Ciudad Real piden que se envíen los bienes a la ciudad para que se anexen a la Real Hacienda, y que los puercos, las sillas de "asentar" y la casa se rematen en almoneda. Las propiedades las adquieren dos españoles: Baltasar de Guzmán y Juan Martín, este último intérprete y traductor del caso.

Otro proceso similar se generó en la región de lo que hoy es la selva lacandona, siendo uno de los refugios por excelencia de los indios que se resistían a la colonización española. Es muy probable que los esclavos africanos también optaran por refugiarse en esta zona, dando por resultado un intercambio cultural.

Gudrun Lenkersdorf (2004) comenta que desde un principio de la conquista de Chiapa, los indígenas mostraron fuerte resistencia al orden colonial, incluso se abstuvieron de dar tributo a los recién llegados. Muchos se fueron de sus pueblos y se refugiaron en la selva, ya que condiciones geográficas lo permitían. La región de la selva lacandona no fue conquistada, sino hasta el término del periodo colonial, por lo tanto fue un territorio que permitía vivir lejos del yugo.

La información de los especialistas antes señalados, Carlos Serrano y Julieta Aréchiga, ayuda a interpretar que es muy probable que los esclavos africanos se refugiaran con los indígenas, a fin de escapar de la esclavitud. Por ello, el mestizaje al cual se refieren los antropólogos, que se desarrolló entre grupos étnicos cohabitantes en la lacandona, sustenta esta hipótesis.

Actualmente en la región tojolabal, en la población de las comunidades de las cañadas del municipio de las Margaritas, Chiapas, cuentan historias sobre el "sombrerón", quien "espanta" a las personas que van a cazar al interior de

${ }^{20}$ AGCA. A1(1). Leg. 235. Exp. 1705. Año 1611. 
la selva. Según los relatos, este personaje es un hombre de color negro con un sombrero grande de piel. ${ }^{21}$ Puede sugerirse que aún quedan vestigios de la memoria colectiva, que pasa de generación en generación, de que existieron en la selva hombres que vivían en ella, y muchas veces les robaban sus productos alimenticios o bien a sus mujeres.

Para reforzar esta idea de que los cimarrones vivían en las zonas despobladas, ya sea bosques o selvas, existe información de tradición oral indígena tzotzil llamada $E l$ negro cimarrón ${ }^{22}$ que narra cómo un negro se roba a una indígena y se la "lleva a las montañas", donde tiene su casa que es una cueva y tiene un hijo. El negro se dedica a asaltar los caminos para poder alimentar a su familia; las cosas que roba las vende en el pueblo junto a la montaña. Lo que demuestra este relato es que hay una visión "negativa" hacia el africano en la vida cotidiana de las comunidades indígenas.

Lo que se puede afirmar es que los esclavos estuvieron en complicidad desde épocas coloniales con los indígenas y que sus rasgos, tanto físicos como culturales, están marcados con esta relación intercultural, pues el africano tuvo un proceso de indianización y el indio uno de africanización. ${ }^{23}$

Para finalizar, es preciso decir que los diferentes procesos de mestizaje mostrados nos ayudan a determinar que la composición del chiapaneco tiene orígenes diversos; aunque la población en su mayoría sea indígena con identidades ancestrales, a lo largo de la historia ha tenido que ir conformando y adquiriendo otros valores culturales. Por ejemplo, un símbolo de Chiapas es la marimba, instrumento que ha dado identidad al estado. Sabemos que en tierras chiapanecas se vio nacer la marimba que hoy conocemos, y que las obras más extraordinarias se han interpretado por músicos de calidad mundial. La marimba es un instrumento mestizo, que tiene aportes tanto indígenas como africanos. Hay evidencias de ello en la historia que no han sido considerados.

Pienso que en Chiapas la principal herencia africana es la marimba, instrumento que llegó con el obispo Juan Cabrera al obispado de Guatemala, en 1612, y con él un grupo de músicos negros de la Habana, ${ }^{24}$ quienes difundieron su cultura y probablemente la marimba. Esta afirmación la hace un investigador guatemalteco, Lester Godínez, quien afirma que la palabra marimba es de origen Bantú. Imba significa "golpes de madera" y el sufijo ma es plural, por lo que quiere decir "multiples golpes de madera".

21 Trabajo de campo en comunidades indígenas tojolabales, en los años 2002 al 2005, con la Brigada Universitaria de la Realidad a la Nueva Esperanza, en las cuales las personas de las diversas comunidades que visitamos, nos contaban estos relatos.

${ }^{22}$ Antonio Gómez Gómez, El negro cimarrón. Ya' y'elaj j-lk’al. 2000.

${ }^{23}$ Luz María Martínez Montiel, Identidad y pluralismo. La presencia africana en América. Seminario Taller. Imagen de la sociedad multicultural.

${ }^{24}$ Antonio Remesal. Historia General de las Indios Occidentales y particularmente de la gobernación de Chiapas y Guatemala, 1971. 
El investigador afirma que la primera evidencia documental es de 1680 , cuando Domingo Juarros cita a Diego Feliz de Carranza y Córdova, durante las festividades de la inauguración de la catedral de la ciudad de Santiago de los Caballeros, y en ella se menciona a la marimba.

De este modo, las herencias culturales del africano se pueden ver reflejadas en la música, en los carnavales, en la gastronomía y en muchos otros elementos que son indispensables para entender al mexicano, y en especial al chiapaneco de hoy.

\section{BIBLIOGRAFÍA}

Archivo General de Centroamérica.

AGCA, A1.23. Leg. 1522. Fol. 57. Año. 1632.

AGCA, A1.23. Leg. 4575, Tomo I, Foja 103v., Año1549. Real Cédula.

AGCA, A1.23. Leg. 1513, Fol. 692, Año 1561.

AGCA, A1.23. Leg. 1512, Fol. 292, Año 1561.

AGCA. A1. Leg. 1512, Fol. 416, Año 1572.

AGCA A.1.1 Chiapas Leg. 234 Folio 01691 Año 1618.

AGCA, A 1.20 Leg. 430. Folio 10365. 1602.

Archivo Histórico Diocesano. Boletín 1. San Cristóbal de las Casas, Chiapas. 1981.

Casillas, Tomás. Testamento. En Boletín del Archivo Histórico Diocesano, Núm. I.

Ramo Dinero y Bienes As, Ecl. Haciendas, conquistadores, Ocotepec. Trascripción: Dolores Aramoni C.

Andrade, Juan.

1990 Economía y sociedad en el Tabasco colonial. S. xv y xVII. Tesis de Maestría. Universidad Nacional Autónoma de México, Facultad de Filosofía y Letras.

Aguirre Beltrán, Gonzalo.

1989 La población negra en México. Estudio Etnohistórico. 3a. ed. México: Fondo de Cultura Económica.

Calderón Diemecke de González, Ofelia.

1973 El negro en Guatemala durante la época colonial. Tesis de licenciatura. Guatemala: Universidad de San Carlos.

Gómez Gómez, Antonio.

2000 El negro Cimarrón. Ya y'ela j-lk'al. Chiapas: unam-Programa de de investigaciones Multidisciplinarías sobre Mesoamérica y el sureste.

Crespo, Horacio.

1998 Historia del Azúcar en México. II Vols. México: Fondo de Cultura Económica. 
González Esponda, Juan.

2002 Negros, Pardos y Mulatos: Otra historia que contar. Tuxtla Gutiérrez, Chiapas: Conaculta-Gobierno del Estado.

2001 "Negros y Mulatos en Chiapas colonial”. En Pardos, mulatos y libertos. Sexto encuentro de afromexicanistas. Adriana Naveda Chávez-Hita (comp.). Xalapa, Veracruz: Universidad Veracruzana.

Herrera, Robinson.

2001 Natives, europeans, and africans in sixteenth-century Santiago de Guatemala. Texas: Universidad de Texas.

Lenkersdorf, Gudrun.

2004 Republica de Indios. México: unam, Instituto de Investigaciones Filológicas, Centro de Estudios Mayas.

Lenkersdorf, Carlos.

2006 "Latinoamerindia”. En América Latina: Historia, Realidades y desafíos. México: Posgrado en Estudios Latinoamericanos-unam.

Level, George.

2000 Conquista y cambio cultural. La sierra de los Chuchumatanes de Guatemala 15001820. CIRMA.

Lourence, Kaptan.

1981 Maderas que cantan. Chiapas: Instituto Chiapaneco de Cultura (Nuestros Pueblos).

Lutz, Christopher.

1984 Historia socio-demográfica de Santiago de Guatemala. Guatemala: Centro de Investigaciones Regionales de Mesoamérica.

Luján Muñoz, Jorge.

1989 Guía del Archivo General de Centroamérica. Guatemala: Ministerio de Educación

Martínez Montiel, Luz María.

1994 "Algunos aspectos metodológicos del estudio de la población de ascendencia africana en México”, El Caribe, 20, México-Cuba, 1993. Cuba: Casa del Caribe.

1998 Identidad y pluralismo. La presencia africana en América. Seminario Taller. Imagen de la sociedad multicultural.

2005 Inmigración y diversidad cultural en México. México: Programa Universitario México Nación Multicultural-unam.

2006 Afroamérica I. La ruta del esclavo. México: Programa Universitario México Nación Multicultural-unAm.

Macleod, Murdo J.

1989 Historia socioeconómica de la América, Central Española. 1520-1720. California: Universidad de California. 
Palomo de Lewin, Beatriz.

1991 Esclavos Negros en Guatemala 1723-1783. Guatemala: Universidad del Valle de Guatemala, Facultad de Ciencias Sociales.

1994 "La esclavitud negra en Guatemala durante el siglo xvı y xvı", en: Historia General de Guatemala. Guatemala: Asociación de Amigos del país. Fundación para la cultura y el desarrollo.

Price, Richard (comp.)

1981 Sociedades cimarronas. México: Siglo XXI.

Remesal, Antonio.

1971 Historia General de las Indias Occidentales y particularmente de la gobernación de Chiapas y Guatemala. Madrid: Atlas. (Biblioteca de autores Españoles).

Rubio Sánchez, Manuel.

1983 Historia del Añil o Xiquilite en Centroamérica. Guatemala: Universidad de San Carlos.

Ruz, Mario Humberto.

1982 Los legítimos hombres, Aproximaciones antropológicas al grupo tojolabal. III. México: unAm-Instituto de Investigaciones Filológicas-Centro de Estudios Mayas.

Soriano Hernández, Silvia.

1994 "Aportes sobre mestizaje de esclavos africanos en Chiapas colonial", Cuadernos americanos. I (8), núm. 43, enero/febrero. unam.

Vila Vilar, Enriqueta.

1977 Hispanoamérica y el comercio de esclavos. Sevilla: Escuela de Estudios Hispanoamericanos.

Vos, Jan de.

1994 Vivir en frontera; la experiencia de los indios de Chiapas. México: Centro de Investigaciones y Estudios superiores en Antropología Social-Instituto Nacional Indigenista.

2002 Una historia para sembrar sueños. Historia reciente de la selva Lacandona 19502000. México: Fondo de Cultura Económica-CIESAS. (Sección de libros de Historia).

Ximénes, Francisco.

1999 Crónica de la Provincia de San Vicente de Chiapas y Guatemala. Intro. de Sáez de Santa María. Cuatro tomos, Gobierno del Estado de Chiapas. 